\title{
УПРАВЛЯЮЩИЕ ВОЗДЕЙСТВИЯ НА ЦИФРОВУЮ ТРАНСФОРМАЦИЮ ПРЕДПРИЯТИЙ ВСЛЕДСТВИЕ КРИЗИСА, ВЫЗВАННОГО ПАНДЕМИЕЙ
}

\author{
(C) 2021 Денисенко Владислав Юрьевич \\ E-mail:Vladizeslav@icloud.com \\ (c) 2021 Нархова Маргарита Алексеевна \\ E-mail: margarita-narhova@yandex.ru
}

Активная фаза цифровизации управленческих и производственных бизнес-процессов за последние пять лет имеет развитие на предприятиях различных направлений. Большая часть предприятий осуществляли существенное финансирование для проведения исследований, проектноизыскательских работ и возможной реализации платформенных систем для существующих и новых бизнес-процессов. Кризис, с которым столкнулись предприятия в 2020 году, связанный с пандемией коронавирусной инфекции внес весомый вклад в части оперативной приоритизации цифровых решений. В статье рассмотрены основные управленческие решения, которые привели к положительной и отрицательной динамике развития цифровой трансформации на предприятиях.

Ключевые слова: цифровизация, управленческие решения, цифровая трансформация, кризис, коронавирус, управленческие процессы, производственные процессы, промышленное предприятие.

Введение. Данная статья посвящена процессу адаптации предприятий к условиям кризиса, вызванного пандемией коронавирусной инфекции, что вынудило организации предпринимать управленческие воздействия в части приоритизации цифровых решений. Цель статьи заключается в том, чтобы показать и проанализировать изменения управленческих решений, которые произошли в период кризиса и какие цифровые инструменты оказались наиболее эффективными в сложившейся ситуации.

Индустрия 4.0 после представления на Германской конференции является отправной точкой в развитии цифровизации на предприятиях $[1,2]$. После окончания конференции о развитии цифровой трансформации или индустрии 4.0 многие страны приступили к формированию нормативной и методологической основы [3], в том числе и в Российской Федерации [3]. Единые документы в виде положения или методики о цифровой трансформации не разрабатывались, поэтому каждая отдельно взятая организация осуществляла цифровизацию индивидуально, распространяя оцифровку на различные бизнес-процессы, как эффективные, так и не совсем. При таком подходе отсутствовал контроль над количеством цифровых проектов, то есть приоритизации цифровых решений не уделяли достаточного времени. Считалось, что в индустрии 4.0 необходимо разрабатывать комплексные решения, затрагивающие все процессы, но в итоге это привело к разбросу стеков технологий и направлений.

Инвестирование денежных потоков организации на развитие цифровых решений для оптимизации существующих бизнес-процессов наступает с кризисом [4]. В первом квартале 2020 года произошли кардинальные изменения в расставлении приоритетов цифровых решений из-за наступления пандемии коронавирусной инфекции. Коронавирусная инфекция затронула все цепочки создания ценности: изменение потребностей, падение спроса на сырье, ограничений ОПЕК+, роста курса и инфляционный скачок [5]. Все перечисленные факторы в итоговом выражении заставили руководство организаций резко оптимизировать свои затраты и пересмотреть инвестиционную политику в отношении цифровой трансформации.

Управленческие решения определяют ключевую роль в стратегических целях, их достижениях или неудовлетворительных результатах. Баланс, который необходимо соблюсти и стрессовые ситуации могут позитивно повлиять при нестандартных решениях.

Активное развитие и продвижение индустрии 4.0 в массы имеет свое влияние не только в качестве информационной активности, но в первую очередь в части достижения новых результатов, применение новых методологий, метрик и построения процесса взаимосвязей промышленной инфраструктурной оболочки. Если 
в текущей парадигме говорится об индустрии 4.0, то в предыдущей версионности, а именно индустрии 3.0 основное направление было на автоматизацию компонентов производства и на управленческие процессы в системах. В основе индустрии 4.0 лежит развитие глобальной промышленной интернет-инфраструктуры [6], что в свою очередь предполагает использование новых платформенных решений в части получения и аналитики больших данных, использование интернет вещей и применения облачных технологий, которые становятся типовыми технологиями для развитых организаций. Но в текущих условиях цифровая трансформация затрагивает изменения бизнес-процессов и осуществления бизнес-моделей предприятий, что не всегда приводит к плодотворному результату. Структура бизнес-моделей организаций базируется на кооперационных взаимодействиях и сетевой модели сотрудничества, а результат деятельности предприятий направлен в большей степени на производство услуг, а не продуктов/ товаров [7, 8].

Процесс организации цифровой трансформации на промышленных предприятиях является неструктурированным и разрозненным. Организации используют существующие бенчмаркт и пытается внедрить/доработать системы. Нагроможденность новыми метриками и изменениями становится катализатором к растягиванию процесса во времени, неудовлетворенности предполагаемым результатом и в целом отказом от цифровой трансформации. Действия руководителей и сотрудников идут в разрез существующим реалиям, что также приводит к конфликтным ситуациям и возможным уходом с действующих постов в роли инициаторов циф- ровой трансформации. Основной причиной, как было сказано выше является - Нагромождение процесса цифровизации. Нагромождение выражается в ухудшении понимания процесса, постоянное обновление методик (чаще, чем раз в полгода), добавление участников согласования, что в конечном итоге приводит к тому, что методический подход и его версионность запутывает сотрудников, а ответственные лица начинают вносить изменения в существующий процесс без информирования заинтересованных сторон. По мнению автора, данная методика должна быть отображена в алгоритме, описанная в виде кросс-функциональной диаграмме понятно и прозрачной для участников и заинтересованных сторон процесса. Методический подход к организации цифровой трансформации должен быть описан и составлены нормативные документы в части внесения изменений: периодичность, согласованность и добавление иных лиц. Изменения не должны осуществляться в период высокоактивной деятельности подразделений по цифровой трансформации в рамках текущего года. Материалы должны обновляться либо в начале года перед началом старта новых цифровых решений или в конце, по итогу года.

Таким образом, необходимо учитывать, что организация процесса цифровой трансформации на промышленном предприятии является основополагающим звеном цепочки в рамках плодотворного старта цифровизации. Грамотный подход к организации процесса позволяет снизить временные издержки на реализацию определенного компонента, а также избежать ненужного дублирования и лишнего согласования с другими участниками.

\section{Библиографический список}

1. Kagermann H., W.Lukas and W.Wahlster, 2011: Industrie 4.0: Mit dem Internet der Dinge auf dem Weg zur 4. industriellen Revolution [Элек- тронный ресурс]. VDI nachrichten, 13.- Режим доступа: http://www.dfki. de/ wahlster

2. Мелешко Ю. В. Индустрия 4.0 - новая промышленная политика германии: теоретическая основа и практические результаты. № 8, 2018 год, стр. 80-93.

3. Положихина М.А. Регулирование процесса цифровизации экономики: европейский и российский опыт. № 4 (101), 2018 год, стр. 64-81.

4. Птицын С. Д.Хромова А. В. Оптимизация эффективности бизнеса с помощью гибкой бизнес-аналитики и анализа данных в условиях кризиса. № 10 (50), 2020 год, стр. 118-125.

5. Зимовец А.В., Сорокина Ю. В., Ханина А. В. Анализ влияния пандемии COVID-19 на развитие предприятий в Российской Федерации. Том 10, № 5, 2020 год, стр. 1337-1350.

6. «Индустрия 4.0»: создание цифрового предприятия // PwC [Электронный ресурс].- Режим доступа: https:// www.pwc.ru/ru/technology/assets/global_industry-2016_rus.pdf 
7. Цифровизация: Практические рекомендации по переводу бизнеса на цифровые технологии; Перевод с англ. М.: Альпина Паблишер, 2019 г. 252 с.

8. Шеффер Э. Преимущества цифровых технологий для производства / Эрик Шеффер: Перевод с англ. М.: Издательская группа «Точка», 2019 г. 320 с. 